\title{
THE AFRICAN STUDENT ASSOCIATIONS' SURVIVAL AND ADAPTATION IN CHINA: CASES OF JINHUA AND WUHAN
}

\author{
TANO Kouassi Joseph a, SUN Qiu Yun ${ }^{\mathrm{b}}$ \\ ${ }^{a}$ Huazhong University of Science and Technology, Abidjan, Cote d'Ivoire \\ ${ }^{\mathrm{b}}$ Huazhong University of Science and Technology, Wuhan, China \\ Corresponding email: tanok75@yahoo.fr
}

\begin{abstract}
This thesis aims to study African students' integration and the adaptation in Chinese universities by joining associative groupings. The thesis uses qualitative research and interviewing target focus groups. It is about a cross-sectional study of descriptive and analytical aiming based on the qualitative under tended by the dialectical approach. The characteristic of this method has made it possible to collect the qualitative data. Within the framework of this study, the information is collected through documentations, recordings of accounts and speeches of surveyed. They are transcribed and the gross profits were the subject of an analysis of contents of the speeches on the Africans students, of the accounts of life stories or experiments lived in the relationship. The results demonstrate that student associations provide students a social identity, a cultural organization, leadership and thus make them feel accepted and socialized in China. Associative space makes it possible for students to acquire communicating and eloquent competence and emotive intelligence. Students who have participated in associative groups support, give them knowledge of organization and human stock management. In this dynamic community, we can also make a report that the composition of these students groupings are minorities sometimes, but those groupings gather together with those who have common interests. As is known to all, there is no difference between the way they associate and forms, except structural and functional perspective.
\end{abstract}

Keywords: Association of African Students, Adaptation, Integration \& Community Life.

\section{Introduction and purpose}

A country which aims to develop its reports/ratios as well as multilateral relationships will control its foreign policy. To consolidate a friendly relationship between the African continent and the new world economic power, thus the education system grants African students to enrich their professional skills. However, how do we know if the Chinese system is favorable to their development? Is the adaptation easy considering many constraints in the empire of the medium? Such are the questions which trotting unceasingly in the reflections of the ones and others from where the importance of an in-depth study within the alive students in China and particularly in the province of Zhejiang (in fact the town of Jinhua) and of Wuhan. Thus, during our research we will be interested in various activities conducted by Cameroonian students and other African students, particularly students from the Ivory Coast, Mali, Niger, Mozambique, South Africa, Egypt, Sudan, Ethiopia, Senegal, Ghanaian, Togolese Beninese, Congolese, etc. These students reside in the following universities: (Huazhong University of Science and Technology, Wuhan University, Hubei University, Ligong University, Zhongnan University, Huazhong Normal University etc). 
Student represents today a new age of the individual cycles of life during which new social roles are exerted. However, community life is often synonymous with "social competition" to such a sign that certain students from the Ivory Coast fear this phase, also "normal" is it. But, if one sticks to the observation of reality of the Ivory Coast, such a vision of community life in student

medium is justified because of the stereotypes and the stereotypes associated with this new statute, thus contributing to give a social figure little satisfactory and no appreciate. We can note that there are more and more associations of the foreign students in China who are creating a little everywhere in universities. This is why we want to be interested so that the students produce when they meet in association and how functions these associations, to include/understand their activities and to explain the mechanisms of their rehabilitation in the even total Chinese company.

Thus, the interest of this study is at the level of the new strategies of social adaptation installation by the students themselves in order to maintain to them reliance at the total company after the process of student's not of socialization which seems a phase of deconstruction of oneself. It is also to show how associations of the students constitute social executives or spaces to enjoy active community life and to attenuate the daily psychological harmful effects related to this one.

We notice that certain students are isolated when they live in margin of associative spaces. That gives an impression to be in margin of the social life. Also, this research has as an ambition of deconstruction or of rebuild of all of these thoughts built around association. Because the evocation of associations generally is founded on a pessimistic ideology giving births to in the spirit from the ones and others the idea from festivity. We thus judged relevant to thus interest us in the importance of community life in academic world the operation of this one.

We must thus propose strategies of implementation of industrial relations policies in favor of the students, of the solutions in terms of actions programmed in connection with the social needs expressed by the students.

It will relate primarily to integration and the adaptation of the African students through the activities of community life, on a description of association, the mechanisms of rebuilding of the students in association and we will finish by the interest and the social representations associated to the students.

From such a point of view, this dynamics of associations of students causes interrogations. In a general, the first associations which see the day in urban spaces gathered people originating in the same area, same ethnic community or of same social professional categories. Thus, Sala N. R.(1993) announces us that the first forms of association appear spontaneously as of the beginnings of the urbanization in urban spaces. These first social networks which, the majority are addressed to youth specifically were inherited the European models during the colonial period. These abstract social structures constitute a framework of integration and structuring of the urban population. They have several social functions according to Delpêch (1983) namely: to perpetuate the relations with the medium of origin; to ensure the integration of the new members within the new urban framework, to cause between the members an idea of the social link and especially to get a social place. In other words, socialize again the individual in urban environment.

As of one time, an expression which underlines it is byBarthélemy Martine, (2000), "associations reflect by their activities the lacks of a company, the weakness of the social link, 
the prolongation of the institutional capacities in particular the State, the local government agencies, the Church, mosque, etc..... who control and support their action with an aim of ensuring the adaptation and the social integration of the individual"; associative vitality falls under the vitality of the social

context. Consequently, the creation of an association answers a precise goal: to solve a problem of social order. In fact, of which social problem could it be a question here since adhesion with an association also reflects variable motivations according to social environments (Kaufmann, 1996).

In fact, how does an association rebuilds and gives direction to the life of the student? Which interest recovers the adhesion of the students to associations? In other words, which are the stakes which this social space conceals and who of this fact constitute today sources of motivations in the students of the Ivory Coast in Wuhan and in Jinhua? Lastly, how the social practices of this field contribute to build the social figure of the student?

Thus, we estimate that through association, the students seek to rebuild the social links and their social identity.

\section{The original framework}

The reduction of the authorized capital is structuring identity deconstruction. Consequently, the life in association is thus perceived as a social space through which the students are rebuilt and a new social identity is also rebuilt. It is thus important to define the following concepts: Community life, social link and social identity.

\subsection{Community life}

To include/understand what we call here community life, it is advisable to define what it is that an association. Then, there have dimensions of community life. Indeed, an association indicates an action to meet durably and by extension, any grouping of determined individuals having shared interests. In other words, an association is perceived like an organization of people continuing of the individual and collective interests (Haeringer, 2008). As such, it is built social more especially as it rises from the interactions produced by the social actors according to their concerns of the moment. Sociologically, association is a concrete social being. In this direction, community life must be apprehended according to a double dimension: a structural dimension and a dimension symbolic system.

By structural dimension, it should be heard as being objective, concrete dimension of association. This one result in the whole of the social behaviors of the students who allow making function association; thus giving life to the community or the groups. In fact, it is the dynamics of the social reports/ratios in associative space and the investment of the students in practice associative (leisure's, meetings, contributions, etc.) that we propose to observe and to analyze (from a social cultural point of view; symbolic system; economic; etc.).

The dimension symbolic system which should be seized here returns to the whole of the system symbolic system, with meaning for the student and who causes his engagement in association. It is acted in fact of the direction which it gives to its action in connection with the practiced activities. That will be to analyze like elements contributing to the manufacture of representations of the student in associative space. But the direction which a student can give to the student's life passes obviously by his report/ratio to the other students through the social reports/ratios which they weave in associative space. This is thus the social reports/ratios which are translated here by the concept of social link. 


\subsection{The social link}

The social link is resulting from Latin "ligamen" "what seeks to attach, a cord", of "ligarer" "to attach, fix, link". Thus, the social links are forms which hold the individual with social groups and the company, which enable him to be socialized, to be integrated into the company and to draw

the elements from them from its identity(Barthélemy Martine, 2000). In light, by social link, it is necessary to hear the diversity of the types of relations which link between the individuals of a community. Thus, we seize this concept through two components: solidarity and sociability.

One already remembers that at the beginning of the 2oth century, Emile Durkheim (1893) had defined two types of solidarity: it is about mechanical solidarity specific to the traditional companies and identifiable organic solidarity at the modern societies. These two forms of solidarity rise according to him from division from social work. It is certainly true that for Durkheim, the modern or complex societies are determined by the second form of solidarity i.e. organic solidarity. But for us, it is not the type of company which imports here but the type of solidarity i.e. organic solidarity. Because, this form of solidarity gives birth to or founds the social link, the social reliance. From this point of view, the social link is built through an individual and collective identity conscience and structures the social roles in associative space. As for the idea of sociability, it is clear that it is not a quantifiable data, nor measurable and difficult to apprehend concretely. Thus, for Georg Simmel, this one returns to multiple exchanges and meetings of all kinds. Sociability is thus a dimension founder of the social link.

\subsection{Social identity}

The question of the identity is complex and is differently tackled in several anthropological, psychological and sociological tendencies.

The identity is a production of two mechanisms. It is of the identity for oneself and the identity for others. Claude Dubar (2000) has written that: "each social actor has a history, a past which weighs on these identities of actors. He is not defined only according to his current partners, of these interactions face to face in a given field of practice; he is also defined according to his social trajectory". In other words, we can say that this one returns to the whole of the subjective provisions able to structure of the representations and to generate practices and who is the product of a history defining the trajectory of the individuals through the social fields.

The objectives of association are:

- The production of ideas, or goods in associations of the African students

- Mechanisms of rebuilding of the students in the African Association and how students integrate through the associative groupings

- The activities of association take part in the manufacture of the social representations associated with the interests of the students. The students are able to adapt to the university system through the associative activities

\section{Methodology of the research}

The Current research is qualitative. A qualitative research makes it possible for the researcher to regard quality as a better study on the human activity and of its impression of the life significant activity. Current research was undertaken by using the guide of maintenance, the maintenance of group, and those files by using semi-structural or semi-directing talks by triangulation. Target population included all the students of the association of the students of the Ivory Coast and 
Cameroonian of the universities of Normal Zhejiang University and Huazhong Unversity of Sciences and Technology chosen by the useful taking away of snowball. In this research, also, a similar interview was made. In the interview, 48 people were implied ( 22 boys and 26 girls). To analyze maintenance, Strubert's (2003) method of 10 stages was applied.

\section{Results}

The results indicated that the following factors are important in the participation in associations of the students: Personal characteristics of the student: the student acquires certain virtues personal through community life such as the self-confidence, extrovert, the emotive intelligence, the individual effectiveness, the competence of communication, eloquent competence, and the competence of comprehension of others. One can also acquire structural factors which are presented in the form of the culture of organization, the climate of organization and a leadership. Basic characteristic: age, sex, level of study; other big factors such as the family, the school and the even group make it possible the students to open out and to adapt indeed because in associative space one is in a family and social space. Environmental factors such as political,

social, economic, cultural and scientific influence ideological character and symbolic system of association.

The analysis in the way in which associations of the students represent the associative groupings will be organized in two parts that will enable us to seize the direction of the choice of a model of control of the students through their association.

\subsection{The ideological level and symbolic system}

They considered it association like an important grouping of integration and leadership of the life which is necessary to be able to assume from any point of view. The students estimate that in student's medium, they gain while being constituted in associative grouping. Within association one learns how to discuss and think in group. It thus makes it possible to learn several virtues such as the development from knowledge and the capacity to learn how to speak into public. One develops the communication, to learn how to appreciate various points of view. It socially incarnates the responsibility and the construction of the human stock management.

The social reports/ratios that the students in association maintain are registered in the process of collective value and symbolic system of the associative grouping. It is the case of the Association of the Students Men from the Ivory Coast of Wuhan. Indeed, the Association of the Students Men from the Ivory Coast of Wuhan does not produce an economy for the individual maintenance with its members. It produces especially a developing ideology of the grouping the associative one in the intention to help the members with better adapting to the academic, social and pertaining to worship situations.

\subsection{The normative and cognitive level}

According to the investigation, we note that the members of various associations of the African students set up a strategy to inform the new students. There are often seminars of information in direction of the new students. Of the question of knowing if associations of the African students in China intervene financially in the event of difficulties of the students, the students think of not being completely satisfied except the monthly contributions. 
We can say that within the associative groupings, the individuals express a need for social recognition. If the participation in the activities of association is a means of realization of the man, it must be also be a means of social distinction and acquisition of the leadership. This is why the students must "normally" make party of at least of an associative grouping with an aim better of adapting or of socially integrating and culturally their values of the country of origin and the country of origin. However, it should be noted that the students within an association acquires values of citizenship and the spirit of courage; responsibilities to which the individual must face.

Let us retain in short that certain African students have especially a vision of the stakes of the associative groupings of the foreign students. For certain students, association created for festive activities, according to other students the associative groupings are set up for contribution getting money.

Nevertheless, a lack of information and sensitizing on the importance of community life in academic world always generates prejudices in the new students.

According the students, to belong to an associative grouping, owes right has to take part in the cultural activities of its country of origin, to build its cultural identity and to learn how to know other foreign cultural values. It is for them, a merit of living together to communicate with other people or students of other nationalities through sporting events such as international competitions (football world cups, Coupe of African football nations, basketball, etc). What

enables them to acquire a competence of communication? In good number of talks, we raise the formulas such as: "For me, association" Mrs. E; Mrs. G: "association is one moment to exchange, to divide, fraternize and to communicate", etc.

The students create opportunities and negotiate through organized social groups a new identity to be socially recognized and to be rebuilt in the leisure. Also, during the various activities the students centralize their emotional ties on the level of the associative grouping and the even group.

\subsection{Regulation and mutual comprehension.}

It arises from the investigation that during the cultural activities, the students estimate themselves satisfied with their participation and especially open out through groups of communication and negotiation. In addition, the majority of the questioned people think that associations of the foreign African students in China contribution to the coil-regulation and mutual comprehension.

As an analysis, we say that, associations of the foreign students in the Chinese universities allow a reinforcement of the social reports/ratios of production, of collaboration and of domination what supports an engagement has to gather in team. Indeed, association affects in an encouraging way and shows sign and feelings of assistance of others. On the other hand, the engagement of the students in the activity apart from associative space aims at filling the absence of the assistance of the biological parents or substitutes parental. Also, associative space allows to the students a better social integration.

To summarize us, let us say that the manufacture of social representations by the students through associative space supports the knowledge of the other organizations and makes it possible to acquire increasing self-awareness with regard to the company. In this direction, the associative groupings remain a channel impossible to circumvent for the students to exchange 
and learn from other external values, to acquire a competence of eloquent and to have a personal effectiveness.

Second question: how an association can rebuild and give direction to the life of the foreign student?

The leadership, it is necessary a good leader for the head of an association, that which can manage, to gather, to manage the men.

\subsection{Cultural activities and social of the African students in China}

With an aim of supporting their insertion or adaptation in the system or the Chinese culture, the African students harness themselves with various activities as well on the cultural level as social.

$\checkmark$ Cultural activities

According to the research undertaken near the African students in China, one realizes that several activities animate the cultural life of the students. Thus, these activities are established according to a calendar not to say a quite precise flow chart. One can quote here:

- The African night: who is an activity which proposes the African culture through fashion shows, traditional dances (following the example Cameroonian makossa or Congolese ndombolo), accounts and poems reporting in a concrete way the life of the former inhabitants of Africa. Traditional songs and several exposures, as well of African usual clothing as of the African braids. Let us specify here that several nationalities are represented the Cameroon following the example of, Ghana, South Africa, Congo, Mozambique, Sierra Leon, Senegal, Mauritania, Egypt, Sudan, Ethiopia.

- Competition of football through which the African foreign students train football teams in order to take part in it. Here, all nationalities are present and the number of footballer is consequent because several African likes to play football. This says this tournament contributes to the reinforcement of various alive communities in China. It is organized each year of the Cups of Africa Nations (EDGE).

- Excursions: in this case of the visits are commonly organized in order to make known with the students the places such as the museums, the parks, in short the places having a strongly cultural value in the spirit of the Chinese. It is the case of the visit organized near the Confucius family considered as a divine idol among Chinese. All nationalities are invited to it but often only the stock-brokers Confucius type often go there.

- Bank holidays: bank holidays will be particularly numerous in China, but one notes here the importance of the Chinese national festival during which several African foreign students harness with various work this for a perfect cohesion of the procession.

- Birthday of the establishment: particularly important since it represents the most effective means to make the propaganda of the university. Indeed many activities are developed such as exhibitions, contests of dance, contests of songs, purely Chinese ceremonies. Thus, with the 6oth birthday, they have a strong service of Cameroonian which leaves their organization, their bravery and their will have particularly contributes to the success of the event. There were dancers, make-up girls, singers, the braiding machines or hairdressers, etc but also note all nationalities present a cultural aspect of their country (traditional dance, history, culture, clothing.) For the dance, there are 12 people who take part including 8 girls and 4 boys. Only 
one person sings it to lie herself of Cameroonian; 1fille makes the make-up and 4 girls make the hairstyle and the braids. Concerning football, more than 100 people take part in this sport.

- Here is reports in a substantial way, the framework of the cultural events of the African foreign students in the town of Jinhua and particularly has Jinhua. However, social activities not to exclude cause for which the countries often gather in association this for communicate in the same direction.

\subsubsection{Social activities}

Many social activities undermine the life of the foreign students in China. Indeed, the fact already of setting up in associations represents an important asset for the insertion of the ones and others because through associations the students have the possibility of gathering, of sharing their idea, their experiment, their problem and even their vision. For the case of associations, the standards are established for not idle the laws enacted by the establishment.

Going in the same impetus, we can quote like social activities the visits organized in other cities. In fact the case particularly Cameroonian each year pays visits in the community's sisters (Wuhan, Shanghai, Hangzhou...). These visits are the symbol of a strong fraternal relation existing between African not to say this African solidarity. Through these visits, the exchanges grow rich socially share their expertise through round tables, debates, the various ones and well of others still.

Also, we have the commonly organized meals in family. What allows the ones and others to remember the many dishes concocts by their mom? The purposes of these meals are to unify the brothers and to make them cultivate the spirit of the division.

Social cases of assistance are necessary, particularly if one of the members of an association is key in a physical or moral way.

* Physical plan: here it is the case of the disease which we put forward. The various members of association must deal with concerned and to bring a beneficial help to him its reestablishment has. Also, let us specify that this help is also in prompt with regard to the happy events. It is the case of the birth of a baby, advertisement of a marriage and amusing news. Always, it is that happiness and misfortune are divided in family.

* Moral plan: the death of a member close to association.

Let us specify also here the importance of the various main roads which often makes it possible the various countries to be found in order to exchange in fraternity in the same spirit.

Like other social activities, we have the Olympic Games organized by the Cameroonian community. The purpose of this activity is to gather all the sportsmen of different the other cities and this, with an aim of a physical blooming. As activities we have football, the handball, Ball tennis shoe, etc.

$>$ Social cultural adaptation of the African students through the associative groupings in China

- The life mode

Many Africans arrive to China after a fashion harness themselves to adapt to the Chinese mode but often run up has several problems.

-The food mode: food represents an important aspect of our life of simply made that malnutrition can be the cause of a severe disease being able to involve a coma. Seen under this 
angle it is important to nourish and balance its food mode well. It is in thus as several African faces the nutritional problem in China; due several food existing in the African kitchen are absent in the box Chinese what creates a serious problem on the level of the food compensation. Moreover dishes and but African are very different from those Chinese, which moreover creates a certain food blocking. Indeed, the African kitchen is very different from the Chinese kitchen what pushes certain students to carry out their own kitchen. So the cost of life costs less and each person to the possibility of giving pleasure while cooking what it likes.

- The language: the language represents a serious blocking especially insofar as it is judicious to serve as communications tools. Indeed, the fact of being misunderstanding or sometimes not included/understood can represent a kind of frustration. Thus the language represents an asset

particularly important insofar as it allows the ones and the others to include itself/understand, to be expressed and avoid any misunderstanding.

\subsubsection{Leisures and hobbies of the African students}

Many African students are from their leisure exposed to the Chinese system. Indeed the particularly hard Chinese laws do not allow the blooming of the students as well Chinese as foreign. So, several African students devote themselves to sometimes useless and sometimes useful leisures. These leisures are many and varied. We have among other things:

- The night exits (bar, nightclub, snack bar, of the KTV) the majority of the African students go in the nightclubs, the bars and snack bar. It is the place where they thus weave friendships with other foreigners the Chinese. In these bars, nightclubs and the KTV learn how to sing in Chinese languages.

- Trips (in other cities). The African foreign students go in places (tourist cities, villages Chinese) at the time of their holidays and of bank holidays, one can among other things quote Beijing, Shanghai, Guangzhou, Hangzhou, Yiwu, Wuhan, etc

- The festivals to decompress (national festivals of the various African countries, festivals of Christmas and Easter for the Christians, Ramadan and tabaski for the Moslems). They are moments of valorization of the African culture, Christian culture and Moslem culture through the various African meals as well as traditional clothing of African origin.

However, let us specify that the activities vary according to the people and the cultures. Other people harness themselves with reading, the kitchen, the cinema, sports, etc.

Finally it realizes that the life of the foreign students is more or less delicate because of the many established laws which have as a consequence only the search for a blooming as well moral as physical, from where all activities enumerated higher.

$>$ Student and community life in academic world

- associative activities

Associations of the African foreign students are political; they defend the interest's social, academic students and takes part in the identity, socialization, the socialization against. Indeed, the students meet once a month for discuss of their condition of social and economic adaptation, of their academic and living condition with an aim of obtaining their diploma successfully, especially to ensure itself to have a good formation in seen to be competitive once with the return in their respective country.

Associations of the African students of meet generally once a month to exchange on their activities, their problems. It is an occasion to maintain the social relationship, the human social 
relations and, the bonds of friendship and of solidarity between them. Also to know mutually. It is also the occasion to exchange and discuss with the newcomers.

The information are vehicle on the social networks by the existing executive office through the social networks like wechat, whatsapp, QQ, etc, these make weekly are an echo growing near a larger audience. The person incharge of associations thus decide the place of the meetings one week before the meeting and informs all the members of the grouping in order to make sure of the reception of the message and the presence of a great number of students.।

$>$ Reception of the new students

Each year, each association organizes the reception of the new students. For this purpose, the old ones make contributions to make the kitchen and that everyone can come together. It is the occasion to discuss and mingle with the new students and to explain the importance of community life to them. It is also the place of explanation again the statutes and rules of procedure of the aforesaid association as well as the conditions of membership. It is thus a question of creating intercultural meetings and exchanges between students.

According to the desires of the organizers and participants, the activities are often organized in one of the university residences which often takes the form of $<<$ night with theme $>>$, according to the calendar or of about a day or even of the sport news and cultural (Christmas, Easter, Ramadan, Tabaski, evening debates, new year, evening official reception, etc). This reception for associations of the African foreign students makes it possible to direct the newcomers towards several academic plan such, social, cultural, etc.

With these occasions, the participants may convey their cultures of origins through test the receipts, of the traditional dishes (meals of their countries of origin), of clothing traditional, the dances, etc It is also has these meetings which the students learns how to organize and hold a meeting, how to communicate with the others and how to better express itself in public, how to become a leader. The former students give councils to the new students compared to their experiments.

$>$ Social network woven through the multiple meetings

Beyond the exchanges, discussions, debates on the topics of topicality, the problems which the students foreigner live, of the assets of university knowledge and so that the period spent in the host country is a positive experiment, it is awaited that the students foreigner tie contacts not only between them but also with the indigenous population.

However, in our experiment, it was confirmed by several studies on the subject (Anquetil, 2006; Papatsiba, 2003; Ogay, 2000), us often shows the opposite: the groups most often attended by the foreign students during a university exchange are the $<<$ students groups of the same nation $>>$ and $<<$ of other foreigner students $>>$ (Budke, 2008, p. 45).

For maintaining and consolidating the contacts on the spot, the African student must be well defined in his actions of listening, responsibility, and leadership and of participation at almost all the meetings. In this effort of participation, the personality of the student hopes certainly much in his effort thus to be integrated in social fabric the access remains the associative spirit in a space of communication, of fraternity, the love and of solidarity. These meetings remain open to all the foreign African students. What also facilitate in a considerable way a project of socialization, can that the foreign students find there circumstances, the moment and the place to tie contacts with people not concerned with their usual medium. 


\section{$>$ Religious Festivities as a cultural factor}

Every year associations of the African foreign students, who are are numerous, have to organize and take part in religious holidays. For the Muslim students, for example, they retain two great festivals, namely: Ramadan and Tabaski. For the Christian students, it is the festival of Christmas and the Easter. With these festive occasions, associations of the African students of Wuhan organize meetings of exchanges, discussions, debates, receipts of their country of origins by taking account of the religious beliefs as higher quotes, of the ballets, the traditional and modern dances of their country, the fashion shows by highlighting the traditional behaviors which reflect the African cultures in its diversities and its variability.

The festivals again are also organized by associations of the African students with an aim of exterior joy and on entering one year hoping to have multiple successes, chances and happiness's in one New Year's Day which is announced with other opportunities. With this occasion, the African students invite other students of other nationalities to take part in this festival. They choose for the majority of the big rooms of festival of the large town halls. These meeting places attract all the students of the various universities of the city. It is also as many occasions of interactions and discovered places of sociability or they gradually learn how to know each other. Many discussions abstract and spontaneous begin between those which make knowledge while being presented and those which exchange news. Certain foreign African students were eager to discover their culture and appreciated the opportunity to be respected and listened. They feel thus at ease to put questions about the company of reception but also to entrust on their problems and to find the solutions. Friendships are formed and thus contributed to weave social link. They are the occasions for the foreign African students to often maintain the reports/ratios of mutual confidence the ones with the other remarkable mediators between the cultures in contact.

From one year to another, the cultural activities change according to the executive office into place. Indeed, each year, the foreign African students take part in the official reception activities and the festival. The place to high light all the cultures and companies present. The African students also take part in the competitions of Chinese language which takes place each year in Beijing

If associations of the African foreign students take part in the social integration of the members, they also support the development of general terms of reference in management of the men and in the animation of team.

\section{Conclusion}

On the whole, regarding community life in student's medium, we questioned ourselves of knowing what an association could again bring to the students or what they produce when they gather in association. In a word, we wanted to know how an association can build and give a direction to the student. That led us to include/understand the social process which underlies the emergence of spaces of sociability in the seniors, the mechanisms which they install in this space to change their living condition. An Association is a space where they come to soak the daily psychological harmful effects then, to draw the essential resources for a new departure.

On the whole, it is advisable to present the assessment of our reflection. But front, it is important to point out the objectives that we fixed ourselves at the beginning. While undertaking to carry out this research on the adaptation and the integration of the African students through community life, we questioned ourselves of knowing what an association could 
again bring to the foreign students African or what they produce when they gather in association. In a word, we wanted to know how an association can it build and give a direction to a student. That led us to study the social process which underlies the emergence of spaces of sociability in the African students, the mechanisms which they install in this space for better integrating and to adapt to the Chinese culture.

As a result, we noted that an association gives a constructive vision, organizational and communication. We thus note that there are a total revolution and a dynamics which takes place today in the associative field. Indeed, the association of the African students arises as a "shock absorbed" of the shocks which the students undergo once they break with the family circle but also like an opportunity of reorganizing. Association is a space where they come to soak the daily psychological harmful effects then, to draw the essential resources for a new departure. So, it is a space of reorganization of the social links because separated from their offspring. So the associative groupings of the African students in China thus become a space of reproduction of the social habitus of the students, but also a channel of mediation between the university personnel and the total company. It gives the fact of social visibility to the students and restores their social identity by the mechanisms of socialization which it sets up through the objectives and ideologies of association. In a word, the associative groupings give another dimension to the student's life by creating the conditions of a student's course succeeded for the active students.

These various reports at the conclusion of our research come from a process of very delicate qualitative investigation which sometimes resembled a kind of invisible negotiation between surveyed and us. The various techniques of investigations used brought great satisfactions to us to the methodological plan. However, we issue reserves as for the results of this research because we will not be able to claim to seize all contours of community life of the African students of China even if the selected approach fits more in one phenomenological vision (i.e. to seek the fundamental causes, to seize the gasoline and the direction of the studied phenomenon). Finally, let us stress that we were interested in the adaptation and integration of the African students through community life. We also realized that they create or seek of the conditions for a better social integration in academic world. Then wouldn't it be interesting to direct future research in direction of the foreign African students who do not attend associations or those who are not African students or other associative groupings not originating in Africa for the purpose of comparing their degree of social integration with those of associations of the African students? 


\section{References}

i. Barthélemy Martine, 2000. Association : un nouvel âge de la participation. Paris: Presse de sciences politiques.

ii. Berry, J., 1997. Immigration, acculturation, and adaptation. Applied Psychology: An International Review, 46(1), pp. 5-34.

iii. Bialek, S. \& Lioyd, A., 1998. Post graduation impact of student leadership. Maryland, College Park: Alexandria V.A American College Personnel Association.

iv. Denzin, Norman \& Yvonna, L., 2000. Handbook of Qualitative Research. 2nd ed. s.l.:Sage Publications.

v. $\quad$ Druguet, S., 2003. La contribution des associations au développement rural, apports spécifiques et intégration dans la dynamique locale : exemple de la Lozère. s.l.:Master of Sciences.

vi. Dubar, C., 2000. La socialisation. Paris: Armand Colin.

vii. $\quad$ Evans \& Nancy, J., 2010. Student Development in College. Theory Research and Practice. s.l.:Jossey-Bass..

viii. Gargano, T., 2009. (Re)conceptualizing International Student Mobility: The potential of Transnational Social Fields. Journal of Studies in International Education, 13(3), pp. 331-346.

ix. Guido-DirBrito, F. \& Bachelor, S., 1998. Development leadership potential through student activities and organizations. New Directions for Student Services, Volume 44, pp. 51-62.

x. Haeringer, J., 2008. La démocratie: un enjeu pour les associations d'action sociale Desclee de Brouwer. Paris: Sociologie et Societé.

xi. Higher Education Policy Institute, 2009. Male and female participation and progression in Higher Education, s.l.: HEPI.

xii. Kaufmann, J., 1996. L'entretien compréhensif; (Collection Université), Paris, Nathan.: Sociologie.

xiii. Kehm, B. \& Teichler, U., 2007. Research on internationalization in Higher Education.. Journal of Studies in International Education, 11(3), pp. 260-273.

xiv. $\quad$ Kouzes, J. \& Elaine., B., 1997. The leadership challenge: How to keep getting things done in organizations. San Francisco: Jossey-Bass.

xv. Yu, G. \& Lee, D., 2008. A Model of Quality of college Life (QCL) of Student in Korea. Social Indicators Research, 87(2), pp. 269-285. 


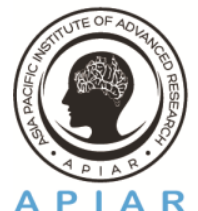

Asia Pacific Journal of Advanced Business and Social Studies

ISBN (eBook): 9780994365675 । ISSN : 2205-6033

Year: 2017 , Volume: 3, Issue: 2

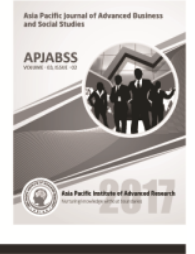

$\sum_{\substack{\infty \\ \infty \\ \infty}}^{N}$ 